Table 2 Postoperative parameters

\begin{tabular}{|l|l|}
\hline Most common complication & Fever (central origin) \\
\hline No. of seizure-free patients & $\begin{array}{l}9 \text { (60\%); transient seizure } \\
\text { in rest 6 (40\%) patients }\end{array}$ \\
\hline Mean duration of MV days & 1.5 days \\
\hline Mean duration of ICU stay & 6 days \\
\hline Mean duration of hospital stay & $39.7 \pm 21.90$ days \\
\hline Motor power at discharge & $\begin{array}{l}\text { Improved in 5 patients } \\
\text { as compared with preop, } \\
\text { worsened in 5atients, } \\
\text { remained the same in } \\
4 \text { patients }\end{array}$ \\
\hline GCS-motor score at discharge & $\begin{array}{l}14 \text { patients had M6 score at } \\
\text { discharge; 1 deteriorated } \\
\text { from M6 to M4 }\end{array}$ \\
\hline
\end{tabular}

Abbreviations: GCS, Glasgow coma scale; ICU, intensive care unit; MV, mechanical ventilation.

\section{A0010 Perioperative Anesthetic Management of a Patient with Chin-on-Chest Deformity Presenting for Reconstructive Spine Surgery: A Case Report \\ Ankur Khandelwal, ${ }^{1}$ Suman Sokhal, ${ }^{1}$ Keshav Goyal, ${ }^{1}$ Surya K. Dube, ${ }^{1}$ Arvind Chaturvedi ${ }^{1}$ \\ ${ }^{1}$ Department of Neuroanaesthesiology and Critical Care, \\ All India Institute of Medical Sciences, New Delhi, India}

Background: Ankylosing spondylitis (AS) can present significant challenges to the anesthetist due to potential difficult airway, cardiorespiratory complications, osteoporotic bones, and increased risk of venous thromboembolism.

Case Description: A 33-year-old woman $(50 \mathrm{~kg} /$ $152 \mathrm{~cm}$ ) presented with extreme fixed flexion deformity of neck as a sequela of AS and was scheduled for corrective surgery. Sensory and motor functions were intact. On airway examination, mouth opening was found to be $3 \mathrm{~cm}$ wide. Evaluation of Mallampati and other airway scorings were not possible. Midline neck structures including trachea were not accessible. Other complicated issues were inability to gargle, lack of landmarks for airway blocks, left-sided deviated nasal septum, and no scope for surgical airway. As a result of anticipated difficult airway, preoperative mock drills were performed. We planned awake fiberoptic intubation (FOI) through the right nostril. On the day of surgery, her airway was prepared using xylometazoline nasal drop, 10\% lignocaine spray (orally) and $4 \%$ lignocaine nebulization. Awake nasal FOI was performed successfully using "spray as you go" (SAYGO) technique. Induction of anesthesia was achieved with fentanyl $(150 \mu \mathrm{g})$ and propofol $(100 \mathrm{mg})$. Rocuronium (50 $\mathrm{mg}$ ) was used during induction. Anesthesia was maintained with $\mathrm{O}_{2}$ :air along with infusions of propofol and fentanyl. No muscle relaxant was administered further in view of motor evoked potentials (MEPs) monitoring. Maintenance of ventilation, circulation, temperature, and DVT prophylaxis were done accordingly. Corrective surgery was done uneventfully with a blood loss of $1,200 \mathrm{~mL}$. The patient was electively ventilated after the surgery and extubated successfully on second postoperative day. She was discharged on the 14th postoperative day without any neurological deficit.

Conclusions: Ankylosing spondylitis and consequent fixed flexion neck deformity bring forth tremendous anesthetic challenges. In this context, the role of preoperative planning, anticipation of complications, and preparedness to deal with complications may not be over-emphasized.

\section{A0011 Efficacy of Targeted Epidural Blood Patch Treatment for Spontaneous Intracranial Hypotension: A Retrospective Study Ramamani Mariappan, ${ }^{1}$ Georgene Singh ${ }^{1}$ \\ 'Department of Anaesthesia, Christian Medical College, Vellore, India}

Background: Spontaneous intracranial hypotension $(\mathrm{SIH})$ is characterized by an orthostatic headache due to CSF leak from dural tear at the spinal level. An epidural blood patch is performed for patients who fail to respond to conservative treatment. In this retrospective study, we wanted to study the efficacy of targeted epidural blood patch (EBP) in terms of the outcome at 3 months.

Materials and Methods: We retrospectively analyzed the charts of patients who received EBP for intracranial hypotension from 2013 to 2018. Age, sex, clinical presentation, site of the leak, site of EBP administration, amount of autologous blood injected, an alternative to blood for EBP, whether it was done awake, under sedation or general anesthesia (GA), number of times EBP was performed, duration of hospital stays, and its clinical and radiological recovery at 3 months were collected.

Results: A total of 16 patients received EBP, of whom 15 received autologous blood and 1 fibrin glue. There were 10 male and 6 female patients. The average age was $39 \pm$ 15 years. An orthostatic headache was the main clinical presentation in 14 (87.5\%). The diagnosis was confirmed and the leak site was identified by MRI. There were 20 leak sites detected in 16 patients, of whom 2 patients had cervical, 4 had upper thoracic (<T6), 7 had lower thoracic (T6-T12), and 3 had lumbar level leaks. Of the 19 injections, 1 was given at lower cervical and 5 -upper thoracic, 8 -lower thoracic, and 5 at the lumbar level. In 14 out of 16 patients, EBP was given either at the site or one level above or below the level of the leak (targeted), and 2 were given at lumbar level (nontargeted). Fifteen injections were performed in the awake state, two under GA, and two under propofol sedation. Two patients (2/16) received EBP twice, 5 days after the first injection. The average amount of blood injected was $27 \mathrm{~mL}$. Upper thoracic leaks received less blood $(20 \mathrm{~mL})$ as compared with other sites. Duration of hospital stay was 5.5 (3-10) days. At 3 months of follow-up, all patients had complete clinical and radiological improvement.

Conclusions: Targeted EBP injection gives complete recovery; both clinically and radiologically. There were no complications of the EBP recorded at 3 months. 